\title{
LA CONSTRUCCIÓN DE LAS HISTORIAS DE LA PAZ A PARTIR DE LA EDAD MEDIA Y DE LA HISTORIA INMEDIATA
}

\section{THE CONSTRUCTION OF PEACE HISTORIES FROM MEDIEVAL AND CONTEMPORARY HISTORY ${ }^{1}$}

\author{
ISRAEL SANMARTÍN \\ Universidad de Santiago de Compostela
}

"But all very clear things are as difficult as rare",

SPINOZA, ETHICS

\section{Resumen:}

En este trabajo se estudia la posibilidad de la construcción de una historia de la paz en la disciplina de la historia. Para ello, conceptualizaremos sus distintas tipologías y los diferentes intentos que ha habido de construir una historia de la paz. Partiendo de dos ejemplos, uno relativo a la historia medieval y otro a la historia contemporánea, mostraremos algunas de las posibles pautas a seguir para integrar la idea de paz en las explicaciones históricas, las cuales se harán desde una perspectiva no teleológica.

\section{Palabras clave}

Historia medieval, historia contemporánea, historia inmediata, paz, non-killing, paz de dios, paz democrática.

\begin{abstract}
In this article we will studie the possibility of the construction of a history of peace into the discipline of history. For this, we will work about the different classifications and different attempts that has had to build a history of peace. Starting from two examples, one relating to the medieval history and another to the contemporary history, will show some possible guidelines to be followed to integrate the idea of peace in the historic explanations, which will be done from a perspective not teleologic.
\end{abstract}

\section{Keywords}

Medieval history, contemporary history, immediate history, peace, non-killing, god's peace, democratic peace.

\footnotetext{
${ }^{1}$ Recibido/Received 30.03.2010. Aceptado/Accepted 16.05.2010
} 
La historia como disciplina científica y como sucesión de los acontecimientos es en buena medida, desde una óptica tradicional, la historia de la guerra, de los conflictos y de las desavenencias, ya sea desde una óptica política, social, económica, intelectual o mismo historiográfica. La historia del mundo es la historia de la guerra o como decía Clausewitz, la guerra es la continuación de la política por otros medios ${ }^{2}$. Los grandes estadistas de la historia han sido guerreros o militares y muchos de los avances intelectuales e industriales han sido realizados para mejorar las armas de la guerra. En buena medida, la modernización de los Estados y los avances económicos han tenido mucho que ver con la historia de la guerra, de los genocidios, de los exterminios, etc. Así mismo, los principales actores colectivos de la historia, los pueblos, las naciones y los Estados han tenido la guerra como un fin en sí mismo ${ }^{3}$. Existe, por tanto, una relación muy estrecha entre los historiadores, la historia y la guerra desde la antigüedad hasta nuestros días que nos puede llevar a concluir que en cierta medida la paz es un concepto negativo en la historia. Vivimos en una sociedad violenta, nos expresamos con un lenguaje violento, incluso por algunos de los que buscan una cierta justicia social, como por ejemplo Frantz Fanon, Malcom X, Stokely Carmichael, C. V. Hamilton o J. P. Sartre. Por eso más que buscar la utopía de una paz lejana y teleológica es mucho más práctico recurrir al movimiento de la "no violencia" $\mathrm{y}$ en especial a Glenn D. Paine y su "no killing society", que lleva a la construcción y consecución de un objetivo claro y totalmente práctica: una sociedad sin matar.

La búsqueda de la paz, la historia de la paz, los "peace studies" no es algo nuevo y hay gente trabajando en esa dirección desde un punto de vista académico desde hace tiempo ${ }^{5}$. Una de las aportaciones más significativas de los peace research ha sido el estudio de los conflictos y la caracterización de la violencia.

\footnotetext{
2 Keegan, John, Historia de la guerra, Planeta, Madrid 1995.

3 Ver Bobbitt, Philip, The shield of achilles. War, peace and teh course of history, Anchor Books, New York, 2002.

4 Ver Mahatma Gandhi, Política de la no violencia, Catarata, Madrid, 2008.

5 Se han cumplido 60 años del programa de estudios de paz en EE.UU en el Manchester College (ver libro Peace and World Order Studies: a curriculum guide). Ver Neil H. Katz, George A. Lopez, "Peace studies: past and future", The Annals of the American Academy of Political an Social Science, July 1989 vol 4, 504, pp.14-22. El planteamiento epistemelógico de la paz se ha llevado a ámbitos científicos y de investigación como Universidades, Institutos especializados, Centros específicos y en general a toda la comunidad científica, ver Wallerstein, Peter, Peace Research, Achievements and challenges, Boulder, 1988. En esta dinámica se incluyen el Center for Global Nonviolence de Hawai y el Instituto Galego de Estudos de Seguranza Internacional e da Paz.
} 


\section{TEORÍA SOBRE LA PAZ.}

Existen dos concepciones en cuanto a la teoría de la paz. La "paz negativa" que es simplemente la ausencia de guerra y la "paz positiva" que es también la carencia de guerra pero con la armonía y cooperación para lograr la seguridad y la justicia en los asuntos humanos. Esta "paz negativa" ha sido dividida en varios campos: los defensores de la paz a través de la fuerza, a través de la justicia social, y a partir de una perspectiva comunitaria. Para algunos autores esta tesis comunitarista se sostiene en un sentido del mundo moral y con una paz duradera para crear una gran nivel de integración basado en la seguridad colectiva internacional, la autodeterminación nacional, la interdependencia económica, y el respecto a los valores culturales. Los comunitaristas creen en cuatro elementos esenciales: interés común, normas, leyes y sanciones, intentando reestructurar la paz con los valores democráticos de seguridad, libertad, justicia y comunidad para que se puedan desarrollar en el nuevo escenario del "Nuevo Orden Mundial" regido por un sistema multipolar, comunitario y global ${ }^{6}$.

Las teorías de "paz negativas" tienen diferentes escuelas. La escuela de la "teoría de la hegemonía", la "teoría del balance de poderes" y la de la "seguridad colectiva". La primera es una teoría marxista que argumenta que desde el siglo XVI el sistema capitalista ha incrementado su dominación principalmente a partir de EE.UU y de Europa Occidental penetrando en las periferias mediante el imperialismo, el colonialismo y el neocolonialismo. Asimismo completan el cuadro un tercer grupo de países que serían la semiperiferia que transmiten plusvalías al Primer Mundo (basada principalmente en Wallerstein) ${ }^{7}$. Esta tesis es inestable y está sostenida en que el poder hegemónico acompañado de la supremacía militar y económica imponen una paz, como fue la "Pax Britanica o la Pax Americana" en el resto del Mundo. Es lo que hizo el presidente Bush cuando proclamó su "Nuevo Orden Mundial", donde los países menos desarrollados tenían que aceptar su lugar como mano de obra barata y ser lugares estratégicos para las grandes potencias. La segunda teoría es la de balance de poderes, que defienden que la paz puede ser lograda mediante la fuerza y persuasión, en competencia por el "interés nacional" de cada país. No pretende ningún cambio en el "status quo" y por eso justifica ple-

${ }^{6}$ Un ejemplo es TEHRANIAN, Majid, "Restructuring for Peace: A Global Perspective" en TEHRANIAN, Katharine and Majid (eds.), Restructuring for world peace. On the threshold of the twenty first century, pp. 1-19.

7 WALLERSTEIN, Inmanuel, The Capitalist World Economy, Cambridge University Press, 1979. 
namente la intervención en la Guerra del Golfo o en las Guerras Mundiales ${ }^{8}$. Por último, la tercera teoría, la de "seguridad colectiva" se fundamenta en la formación de instituciones internacionales que aseguren una seguridad de todos, como la ONU.

En cuanto a las teorías "positivas de paz", defienden el uso de la justicia, y sólo algunas tendencias reconocen el uso de la violencia bajos determinadas condiciones. Hay tres escuelas. La teoría de la "Ley internacional", la de la "integración internacional" y la teoría de la "resistencia sin violencia". La primera se basa en artículos sobre las disputas internacionales ${ }^{9}$. La segunda teoría de la "integración internacional" o "teoría de telaraña"10 mantiene que aunque la ley internacional ha deslegitimado el uso de la fuerza, ésta no se ha excluido. Esta escuela internacional cree en una interdependencia entre estados nación que han maximizado los costes y minimizado los beneficios del uso de la fuerza, por eso también es conocida como teoría neo realista o de la interdependencia ${ }^{11}$. Por último, la teoría no violenta se apoya en los presupuestosde Gandhi ${ }^{12}$, que es donde se integraría ideas como la del "no-killing".

\section{LA HISTORIA DE LA PAZ.}

La historiografía ha prestado mayor atención a la guerra y a los conflictos, cuestión que ha contribuido a legitimar el belicismo, la violencia y el poder destructivo como formas inevitables de progreso. En esta concepción la guerra es vista como motor de la historia y como elemento teleológico al cual y por el cual avanzaría la humanidad. En este argumentario, el concepto de paz surge a partir del de guerra, en donde hay un preconcepto de paz relacionado con el altruismo, la cooperación, la solidaridad o el amor.

\footnotetext{
${ }^{8}$ El principal teórico fue MORGENTHAU, Hans, Politics among Nations: the Struggle for Power and Peace, Aflred K. Knopf, New York, 1978.

9 FALK, Richard, Frederich Kratochwil and Saul Mendlovitz, International Law, A Contemporary Perspective, Westview, Boulder, 1985.

10 Ver BURTON, John, Global Conflict: The Domestic Sources of International Crisis, University of Maryland, College Park, 1984.

11 KEOHANE, Robert O. and Jospeh S. Nye Jr, Power and Interdependencie, Glenview, 1989.

12 GANDHI, M. K., An Autobiography: The Story of My Experiments with Truth, Penguin, 1984; UNNITHAN, T. K. N., Change Without Violence: Gandhian Theory of Social Change, Gujarat Vidyapith, Ahmedabab, 1987.
} 
La construcción de una historia de la paz es algo complejo. La investigación para la paz enmarca la historia para la paz y sus presupuestos metodológicos y las nuevas categorías analíticas e instrumental de estudio con un gran afán de interdisciplinar. La historia de la paz equilibra la disfunción historiográfica entre la valoración y la extensión que se ha otorgado a la guerra respecto a la paz y a las situaciones de crisis resueltas por medios violentos en comparación con las muchas experiencias de resolución pacífica de conflictos. En el mismo sentido, ayuda a comprender el presente y a planificar el futuro a través del conocimiento del pasado para llevar a los grandes retos de nuestro tiempo: la convivencia en paz de los miles de millones de habitantes del planeta ${ }^{13}$.

El historiador tiene una gran responsabilidad en la construcción de imaginarios, de hitos culturales y sociales, de parámetros políticos, y su formación es clave para la construcción de futuros pacíficos donde se ponga en relación la ciencia (es decir la historia) y la ética, que es en buena medida el eje sobre el que versa este trabajo ${ }^{14}$, puesto que las demandas de paz y del "no-killing" surgen del compromiso y de las propias víctimas.

La investigación para la paz se ha ido haciendo un hueco en la disciplina de la historia. No sólo en cuanto a las propuestas y pensamientos de los movimientos sociales pacifistas, la no violencia, la importancia de los grupos alternativos y la construcción histórica de la paz, sino también en la forma en la que se abordan los propios problemas históricos: la visión de los conflictos, los actores, la metodología, las contradicciones que pueden aparecer entre el modelo antropológico utilizado y los resultados o la excesiva importancia de algunos actores (como los Estados) en detrimento de otros ${ }^{15}$.

Los humanos tienen que afrontar que el conflicto es parte del proceso de interacción social pero tal como sucede se puede solucionar. Las relaciones sociales y la socialización crean desigualdades entre los individuos y las sociedades. Los humanos no son violentos o pacifistas sino que pueden solucionar sus problemas de una forma pacífica o violenta, aunque hay que precisar que la violencia es parte de la concepción histórica occidentalista y eurocéntrica . La historia está llena de conflictos pero la regu-

13 Francisco A. Muñoz y Mario López Martínez (eds.), Historia de la Paz. Tiempos, espacios y actores, Instituto de la Paz y los Conflicos Universidad de Granada, Granada, 2000, pp 1-10.

14 Gracias a Joám Evans Pim por "prestarme" esta idea.

15 Francisco A. Muñoz y Mario López Martínez (eds.), Historia de la Paz. Tiempos, espacios y actores, pp 21-22. 
larización pacífica ha tenido también mucha influencia. Desde todas las experiencias y estancias se han desarrollado resolución de conflictos y negociaciones que han llevado a una regulación pacífica: firma de tratados de paz, solidaridad, cooperación, etc.

De lo que estamos hablando en este trabajo es del desarrollo del "no killing" en la historiografía y en la historia, para lo cual debe de ir asociado a dos conceptos en los que colabora muy estrechamente. Son, por un lado, la idea de una "paz positiva", es decir, una paz construida a medida que la historia acontece y se sucede en relación a un argumentario sostenido en la justicia, igualdad y resolución de conflictos. Por otro lado, está la idea de "violencia estructural" que es toda la violencia contenida en la sociedad, en la propia comunidad de historiadores y en todas las relaciones de poder.

Con estas ideas se renuncia explícitamente a la idea de "paz absoluta", una idea utópica y teleológica en muchos casos utilizada de forma que favorece lo violento. Se trata, más bien, de la regulación, transformación y resolución de los conflictos en el acontecer de los acontecimientos por parte de los humanos tanto colectiva como individualmente.

En otro sentido, también es necesario tener en cuenta que el concepto de guerra siempre es presentado como un concepto "totalizador". Cuando en la historiografía se habla de la "Guerra de los cien años" de la "Guerra de los treinta años" estamos dando por sentado que hubo confrontación durante todos esos años cuando no es cierto, lo mismo sucede cuando nos referimos a la Primera y Segunda Guerra Mundial o la Guerra Fría, donde no hubo una implicación de toda la población mundial.

Aquí nos tenemos que parar en ideas como la del "no killing", hay que tener en cuenta que las bases de esta propuesta sostenidas en las ideas del profesor Glenn D. Paine defienden que si las raíces de la violencia están en la biología humana, debemos de cambiarlas, si está en la familia o en la socialización tenemos que alterarla, si está en las estructuras económicas debemos de rectificarla, y si está presente en las culturas debemos de crear alternativas. Paine propone que la sociedad debe de tener presente el "no killing" para que la tecnología no sea diseñada para matar ni para su justificación cultural, al mismo tiempo que ni las condiciones sociales ni económicas han de ser mantenidas para el uso de la violencia ${ }^{16}$. En definitiva, se trataría de

16 Ver Paine Glenn D., Nonkilling Global Political Science, Center for Global Nonviolence, Hawai, 2002. 
colaborar desde la historia y la historiografía para ayudar a la creación de una sociedad global donde el "no killing" sea posible. En este sentido, es preciso señalar que los hombres pueden matar o no pero la mayoría no lo ha hecho y que el ejercicio del poder necesita "amos" pero también necesita "esclavos" y sin estos últimos aquellos no son nada, con lo que la coerción ejercida por el poder puede ser perfectamente desactivado si la sociedad tiene unos mecanismos diferentes de funcionamiento.

\section{LA CONSTRUCCIÓN DE UNA PAZ TELEOLÓGICA EN LA EDAD MEDIA.}

En la Europa de la alta Edad Media (VIII-IX) la idea de paz sirvió para buscar el reequilibrio político, la armonía social, la oposición al pillaje y la violencia, y hasta fue fundamental para el rearme espiritual. Así surgió la llamada "Paz del Rey", que fue un concepto jurídico de origen germánico surgido durante la Alta Edad Media y que se refirió en un primer momento a la protección jurídica de la persona del soberano. Por derivación, se extendió a los lugares que el monarca habitaba y los caminos que transitaba. Después fue usado para proteger mercados, ferias, personas, lugares. Esta paz regia dio lugar al concepto de paz territorial.

La Iglesia encabezó también importantes movimientos a favor de la paz puesto que disfrutaban de habituales enfrentamientos con los señores feudales y se plasmaban en constantes episodios de rebelión, desobediencia y guerras, aunque hay que tener en cuenta que surgen en momentos de crisis y no cuestionan en lo esencial las fuentes del poder establecido

En este contexto se rescatan diferentes ideas de paz. Así surge la Paz de Dios (Pax Dei), que suponía limitar las acciones violentas contra los eclesiásticos y sus propiedades y también contra los pobres (después se extendió al resto de la población). Esta protección se manifestaba en la solicitud de una especie de salvoconducto para todos los no combatientes y sus bienes. En Alemania se logró una cierta paz pública mientras que en el sur de Francia la autoridad de los reyes estaba en franca competencia con el poder de los señores feudales, por eso la "paz de Dios" tuvo éxito ahí. Todo esto quedó reflejado en las deliberaciones y términos de los debates sobre pactum pacis, constitution pacis, retauratio pacis et justiciae, pax reformanda, etc. de los concilios de Charroux-en-Poitou (989), Puy-en-Velay (990), Limoges (997) y Poiters (1000). Roberto el Piadoso la proclamó en Francia en 1010-1011 y contra los que violasen su juramento se previeron sanciones diversas. 
También fue importante la Tregua de Dios, que limitaba en el tiempo la realización de actos violentos, impidiendo a los cristianos luchar durante ciertos día de la semana o durante ciertas fechas. Estas proposiciones tuvieron su primera expresión en Provenza pero se expandieron hacia otros lugares de Francia (Aquitania, Borgoña, Normandía, Besançon, etc.). Finalmente estos acontecimientos tuvieron su repercusión en el conjunto de poderes públicos, especialmente reyes y príncipes, al pasar de una paz personal y temporal hacia una paz territorial en la que se proclama triunfante el derecho publico frente al derecho privado ${ }^{17}$.En ese movimiento participaron no sólo autoridades eclesiásticas, sino también las autoridades políticas y los diferentes movimientos sociales (hermandades, municipios) lo que nos indica la permeabilidad de esas ideas y su posible interacción en la toma de decisiones. Una manifestación práctica de todas cuestiones la representaron las agrupaciones de herejes: cataros, husitas, valdenses ${ }^{18}$, que llevan al ultimo término la interpretación de tregua y paz de Dios porque se oponían a las formas de guerra, a matar a sus semejantes, e incluso a predicar la "no violencia" y el amor como eje central de la convivencia política. En el mismo sentido, está la creación de la promoción de caballeros de la paz y la creación de milicias de la paz, motivadas por la oposición a los señores feudales y contra los poderosos.

En todas estas manifestaciones, la paz aparece como un valor espiritual asociado a la equidad y la justicia. La otra parte de todo esto es que no cuestiona las formas de violencia institucionalizadas o no, así como las guerras (defienden el término de "guerra justa"), la desigualdad económica, social, etc.

Además de todo esto también la paz estaba presente en los diferentes tratados y en las diferentes elaboraciones de planes de paz como el contenido en la obra de Pierre Dubois (De Recuperatione Terre Sancte, 1306), Dante Aligheri (De Monarchia, 1310), Marsilio de Padua y Juan de Jandum (Defensor Pacis, 1324), etc.

A pesar de todo esto, lo siglos XIII-XV están presididos por diferentes guerras en el Occidente Europeo. En cierta medida, la guerra fue causa y consecuencia de la crisis demográfica, agrícola y social, de las diferencias entre Señores feudales

17 Francisco A. Muñoz y Mario López Martínez (eds.), Historia de la Paz. Tiempos, espacios y actores, pp. 412-413.

18 Ver Baschet, Jérôme, La civilisation féodale. De l'an mil à la colonisation de l'Amérique, Flammarion, Paris, 2006, pp. 300-310. Díaz del Corral, Eulogio, Historia del pensamiento pacifista y no-violento contemporáneo, Hogar del libro, Barcelona, 1987, pp.26-40. 
para ampliar su poder, y de las resistencias de campesinos y trabajadores urbanos, así como de la voluntad de extirpar las diferentes herejías mediante la fuerza y resistencia. La llegada de la peste a Europa a mediados del siglo XIV también contribuyó a todo ello ${ }^{19}$. De toda esta situación se concluyó que la guerra era beneficiosa para sus practicantes, como se puede comprobar en diferentes cronistas bajomedievales (Honoré Bouvet, Christine de Pisan o Geoffroy de Charny) ${ }^{20}$

En este sentido, el año 1000 ha sido un año de grandes debates historiográficos sobre si su significado fue de gran cambio (Duby) o de continuidad (Barthélemy), una polémica que va asociada a toda una serie de terrores al fin del mundo y de la segunda llegada de Cristo, que traería la paz eterna ${ }^{21}$. Aunque no hay consenso, unos autores apuestan porque el año 1000 fue un momento intenso, de gran violencia señorial y de convulsiones que llevaron a la mutación feudal, para otros sólo es un momento de tensiones sociales exageradas por la instauración de un nuevo orden feudal. Según otras interpretaciones ni hubo mutación feudal ni escatología.. Sea como fuera, el monje cluniacense Raoul Glaber habla de un mundo nuevo y lleno de optimismo ${ }^{22}$.

El anticristo tiene una importancia fundamental en el imaginario medieval y a el se le asocian los cataclismos, etc. Los primeros cristianos fijaron en el año 500, aunque después fue "aplazado" al año 800, 970, 981, 992, 1065 y 1250. El Abad Odón de Cluny estaba convencido de la venida del anticristo, en el siglo XII, las primeras cruzadas se desarrollaron bajo la amenaza de un clima del fin del mundo. Durante el siglo XIII la preocupación por el Anticristo no ceja. En 1260 surgieron en Italia diferentes movimientos de penitentes y flagelantes. La peste negra de 1348 revivió la inquietud y suscitó un nuevo movimiento de flagelantes. También durante el gran cisma que dividió a la Iglesia entre 1378 y 1417 el Papa es calificado de Anticristo. Todo esto es visto por teóricos como Reinhart Koselleck quien afirma

\footnotetext{
19 Ver Biraben, Noël, Les Hommes et la Peste en France et dans les pays européens et méditerranéens, Paris-La Haye, Mouton, 2 vol., 1976.

20 Ver Fernandez, Jon A., "Guerra y sociedad en europa occidental durante la Baja Edad Media (ss XIII-XV)", en AA.VV., La guerra en la historia, Universidad de Salamanca, Salamanca, 1999, pp. 45-97.

21 Sobre los terrores del año 1000, Georges Duby, L'an mil, Paris, Gallimard, 1980; Dominique Barthélemy, La mutation de l'an mil a-t-elle eu lieu?, Paris, Fayard, 1997; Sylvain Gouguenheim, Les Fausses Terreurs de l'an mil, Paris, Picard, 1999; y Robert Moore, La Première Révolution européene (X-XIII siècle), Paris, Seuil, 2001.

22 Ver Baschet, Jérôme, La civilisation féodale. De l'an mil à la colonisation de l'Amérique, p. 121-124.
} 
que es una estrategia para integrar la escatología en los tiempos presentes, como elemento de la estabilidad de la Iglesia y de su dominación.

En la misma línea y relacionado con esto surgieron toda una serie de movimientos apocalípticos, milenaristas y heréticos en los que tuvo gran influencia el Apocalipsis de San Juan, que tuvo en la cultura medieval un gran impacto tanto en la teología como en el arte. En esta oportunidad, el Apocalipsis no concierne sólo al fin del mundo sino al pasado, presente y futuro de la Iglesia y a un conjunto de movimientos sociales. Eso lleva a interpretaciones milenaristas (variantes de la escatología) que pronostican un futuro asociado a la fase última de la historia universal, aunque lejos de anunciar el fin de los tiempos y la destrucción del mundo prometen el preámbulo del reino de Cristo sobre la tierra, estableciendo para todos los hombres un orden paradisiaco de paz y de justicia. Aunque hay un gran debate al respecto, algunos tomando a San Agustín y a la La Cité de Dieu asocian el milenium a aquel momento histórico, mientras otras interpretaciones más literales de la Palabra sagrada incidían en un futuro que vendrá..San Agustín pensaba que la paz es un bien y no hay otro mas valioso y útil. Su idea fue "combatid sin violencia por la verdad" y con los herejes "combatid con la discusión y venced con la razón"

Otro de los autores clave en la idea de milenarismo fue Joaquín de Fiore, abad de un monasterio cisterciense de Calabria y quien habla de la realización de una iglesia espiritual. Sus ideas tuvieron mucho éxito entre los franciscanos y los dominicos. Aunque el punto culminante del milenarismo medieval por su apoyo popular y por el empleo de la fuerza fue con la insurrección husita, movimiento encabezado por Jean Hus. El milenarismo permite la manifestación de la transformación social radical ${ }^{23}$ Claude Carozzi, Apocalypse et salud dasn le christianisme anciene et médiéval, Paris Aubier, 1999.

Cambiando de tercio, podemos concluir que las guerras en el medievo transforma las sociedades que en la actualidad comprenderían a Francia e Inglaterra ${ }^{24}$

Sea como fuere, ambas teorías tienen un gran componente teleológico puesto que buscan la paz como un fin y como un organizador externo de los propios acon-

\footnotetext{
23 Ver Norman Cohn, Les Fanatiques de l'Apocalypse, Paris, Payot, 1983

24 Philippe Contamine et Olivier Guyotjeannin (dirs), Guerre et violence. La guerre, la violence et les gens au Moyen Age, Paris, 1996 y Christopher Allmand, The hundred years war. England and france at war c.1300-c.1450, Cambridge University Press, Cambridge, 1988.
} 
tecimientos históricos e historiográficos. La guerra y la paz en la Edad Media tienen un gran componente de fuerza y abuso. La violencia supone ejercer una fuerza moral o psicológica para imponer, coartar forzar o obligar, y la Iglesia la utilizó para lograr sus fines mediante construcciones teóricas con fuerte impacto social como el milenarismo, el apocaliptismo o la idea del fin del mundo.

\section{LA HISTORIA INMEDIATA COMO EJEMPLO DE SOCIEDAD PRE- PARADA PARA LA VIOLENCIA.}

Después del final de la Guerra Fría se conservaban determinadas actitudes y lógicas de su funcionamiento como la búsqueda de enemigos "visibles" y declarados o el pensamiento bipolar, etc., pero también aparecieron ideas nuevas como el interés en resaltar

la victoria del capitalismo frente al socialismo y la de EE.UU frente a la URSS. Todo englobado en una perspectiva finalista con un carácter optimista, buscando la evolución teleológica y con un sentido partidista a la historia. Dentro de estos parámetros podemos asociar los pensamientos de Francis Fukuyama y su tesis de "el fin de la Historia", el de Samuel Huntington sobre el "choque de civilizaciones" y el de Robert Kagan en relación a la "brecha transatlántica"

\section{Interpretaciones para explicar la nueva situación:}

a) Un solo mundo: euforia y armonía. Fue una explicación aceptada por políticos e intelectuales que esperaban que la ONU tuviera una importancia nueva en un marco de paz $^{25}$, no obstante, esta tesis fue un espejismo, y se multiplicaron los conflictos étnicos, el surgimiento de grupos de extrema derecha e izquierda y la intensificación del fundamentalismo religioso. En 1989-91, los EE.UU, una vez "ganada" la Guerra Fría, rápidamente se quitaron la careta y declararon el "Nuevo Orden Mundial" donde con la permisividad de la ONU empezaría una nueva era militar, que cristalizaría en la Guerra del Golfo. Este "New World Order" no se diferenciaba mucho del "realismo" de Nixon y Kissinger, pero carecía de su retórica.

25 Huntington cuenta en su libro a modo de anécdota que "el rector de la universidad más importante del mundo vetó el nombramiento de un profesor de estudios sobre seguridad porque su necesidad había desaparecido". Ver HUNTINGTON, S., El choque de civilizaciones y la reconstrucción del orden mundial, p. 35. 
En el caso de Fukuyama, su tesis sobre el "fin de la Historia" proponía un mundo de paz entre las grandes democracias occidentales, aunque quizá no dentro de ellas, -lo que llamaba poshistoria-, pero podía ser, y era, un mundo de guerra para el Tercer Mundo (ejemplificado en Irak desde el primer momento). Podríamos definir la nueva situación como de "paz caliente"26, es decir, con la amenaza del terrorismo, la pobreza, la represión política, las trágicas guerras focalizadas, la deuda externa, el caos, el exceso de poder, la ineficacia de gobiernos y Estados, la inestabilidad política y monetaria, y el problema ecológico, se podía hablar de una "paz formal" pero muy "caliente" en cuanto a conflictos no declarados (todos los citados) y los declarados (sobre todo en el Tercer Mundo). Esa idea de "paz caliente" se basaba en el retorno del unilateralismo de EE.UU y en una nueva bipolaridad Norte Sur.

b) Dos mundos: nosotros y ellos, que se explicaba el mundo de una manera bipolar entre "zona de paz" y "zona de conflictos"; Occidente y resto del mundo; países ricos y pobres. Algunos autores que defendieron esta interpretación fueron Max Singer, Aaron Wildavsky y Robert O. Keohane ${ }^{27}$ o Kishore Mahbubani con "The West and the Rest". Esta explicación es demasiado simple para un mundo demasiado complejo.

c) 184 Estados, es decir, un mundo basado en la teoría "realista" de las relaciones internacionales, donde los Estados serían los actores principales en los asuntos mundiales e intentan maximizar su poder para asegurar su superviviencia y seguridad. Cuando un Estado se ve amenazado se alía o refuerza su poder para defenderse. Esta tesis es una explicación no válida para el nuevo mundo puesto que no todos los Estados actúan igual, ya que tienen que atenerse a las reglas internacionales y los Estados han perdido parte de su poder, funciones y soberanía con las instituciones internacionales ${ }^{28}$.

d) Caos. Esta explicación subrayaba la quiebra de la autoridad gubernamental, la desintegración de los Estados, la intensificación de los conflictos tribales,

${ }^{26}$ Inspirándonos en BUARQUE, Cristovam, The end of Economics? Ethics and the disorder of progress, Zed Bokks, New Jersey, 1993, p. 152.

27 Max Singer and Aaron Wildavsky, The Real World Order: Zones of Peace, Zones of turmoil, Chathan, Nueva Jersey, 1993; Robert O Keohane, Nye and Stanley Hoffmann (Comps.), After the Cold War: International Institutions and State Strategies in Europe, 1989-1991, Cambridge, Harvard University Press, 1996; James M. Goldgeier y Michael McFaul, "A Tale of Two Worlds: Core and Periphery in the Post-Cold War Era", en International Organization, nº46 (primavera de 1992).

28 Esta tesis fue apoyada por WALTZ Kenneth, "The Emerging Structure of International Politics", International Security, no 18, otoño 1993, pp. 44-79; MEARSHEIMER, John J., "Back to the Future: Inestability in Europa after the Cold War", International Security, nº15, verano de 1990, pp. 5-56. 
étnicos y religiosos, la aparición de mafias criminales, la proliferación de armas nucleares, la difusión del terrorismo, etc. Sus defensores fueron Zbignew Brzezinski, Daniel Patrick Moynihan o Robert Kaplan ${ }^{29}$. Esta estrategia explicativa es poco útil y falta teoría para explicar la situación.

e) La teoría de "choque de civilizaciones", defendida por Huntington principalmente, sostenía que los estados se asocian según su cultura común o semejante y que los conflictos entre Estados se producen por sus diferencias culturales. "Es poco probable que las sociedades y los estadistas vean surgir amenazas de un pueblo al que creen entender y en que creen poder confiar porque comparten con ellos la lengua, religión, valores, instituciones y cultura. Es mucho más probable que vean amenazas procedentes de Estados cuyas sociedades tienen culturales diferentes y a las que, por tanto, ni entienden ni creen dignas de su confianza" ${ }^{30}$, explicaba Huntington, quien pensaba que su explicación incluía a las otras cuatro anteriores puesto que, según él, su explicación era compatible con las demás e incorporaba elementos de ellas. Aquí el problema era lo que él entendía por civilización y cómo explicaba lo que era. De esta tesis surgió más tarde la tesis de Robert Kagan sobre la "brecha transatlántica", que pronosticaba un enfrentamiento de Occidente (EE.UU) contra Occidente (Europa).

Estas cinco interpretaciones se agruparon en cuatro escuelas. Por un lado la escuela de "el fin de la Historia"; otra que advertía el principio de un mundo menos amenazante; una escuela denominada de "continuidad y cambio"; y una última que auguraba un escenario de guerra. La primera explicaría el mundo en términos de paz, aburrimiento e inercia dominados por los valores estadounidenses; la segunda insistiría en que con el declive de las grandes superpotencias desaparecerían las amenazas militares y nucleares (es una tesis de euforia); la tercera miraba más bien al pasado para encontrar coincidencias y novedades en la historia ${ }^{31}$; y la última se basaba en un escenario de conflictos (el choque de civilizaciones).

29 BRZEZINSKI, Zbigniew, Out of Control: Global Turmoil on the Eve of the Twentyfirst Century, Scribner, New York, 1993; MOYNIHAN, Daniel Patrick, Pandaemonium: Ethnicity in International Politics, Oxford University Press, Oxford, 1993, KAPLAN, Robert, "The Coming Aranchy", Atlantic Monthly, n 273, february 1993, pp. 44-76, ampliado después en el libro: KAPLAN, Robert, D., La anarquía que viene, Ediciones B, Barcelona, 2000.

${ }^{30}$ HUNTINGTON, S., El choque de civilizaciones y la reconstrucción del orden mundial, p . 37.

31 THOMPSON, Kenneth W., Traditions and Values in Politics and Diplomacy. Theory and Practice, pp. 323-329. 
Existen diferentes teorías para explicar la paz en el escenario internacional:

a) La del liberalismo económico ${ }^{32}$ que considera que los requisitos para la paz no descansan en preceptos militares sino económicos: el deseo de lograr prosperidad, la interdependencia de Estados y la cooperación internacional de regímenes. El problema de esta teoría es claro, el sistema internacional es anárquico y no responde sólo al estímulo económico sino social, político, etc.

b) La tesis que sostiene que las guerras "tradicionales" ya no tendrían lugar (algo que cae por su propio peso si miramos los conflictos en marcha en la actualidad).

c) El razonamiento que presume de la tendencia a la paz de las democracias, también denominada tesis de la "paz democrática", que es defendida entre otros por Michael Doyle ${ }^{33}$, y en la que se basaban autores como Fukuyama (quien llegaba a Kant a través de él). Este tesis muestra cómo el ensayo kantiano de La Paz Perpetua podía ser utilizado como una explicación coherente de dos importantes regularidades en la historia mundial: la tendencia de los Estados liberales a ser pacíficos en sus relaciones mutuas y belicosos en sus relaciones con los Estados no liberales. Esta es una tesis con una fuerte impronta del liberalismo en su configuración social, política y económica, y que tiene en cuenta que:

Doyle hace una interpretación de Kant, quien recogió la idea de la "paz perpetua" del abate de Saint Pierre, y a partir de la cual publicó en 1795 su opúsculo La paz perpetua. En él se proponía la formación de gobiernos democráticos, la instauración de una federación de Estados libres y la constitución de un derecho cosmopolita ${ }^{34}$. Para

32 En autores como Richard N. Cooper, Enrst B. Haas, Joseph S. Nye, Robert O. Keohane (que colaboró con Fukuyama), David Mitrany y otros. Ver MEARSHEIMER, John J., "Back to the future. Inestability in Europe after the cold war”, International Security, Vol. 15, nº1, Summer 1990, p. 42.

33 Especialmente en su ensayo "Kant, liberal legacies, and Foreign Affaris", Philosophy and Public Affairs, Vol. 12, n³, summer 1983, pp. 205-235 y "Kant, Liberal Legacies, and Foreign Affaris, part 2", Philosphy and Public Affairs, Vol. 12, n4, Fall 1983, pp. 323-353. Para seguir la discusión ver DOYLE, M. W., "Reflections on the Liberal peace and Its Critics", en M. E. Brown, Sm. Lynn-Jones y S. E. Miller (eds), Debating the Democratic Peace, Cambridge, 1996. También ver: DOYLE, Michael, "Liberalism and World Politics", American Political Science Review, Vol. 80, n4, december 1986, pp. 1151-1169; MEARSHEIMER, John J., "Back to the future. Inestability in Europe after the cold war", International Security, Vol. 15, nº1, Summer 1990, p. 48.

34 Kant introducía junto al derecho estatal y el derecho internacional, el derecho cosmopolita. Para una lectura crítica, ver: VELASCO ARROYO, Juan Carlos, "Ayer y hoy del cosmopolitismo kantiano", Isegoría, n¹6, 1997, pp. 91-117. 
muchos autores, a pesar del cambio de marco histórico y la obligada reformulación necesaria, los conceptos básicos del ensayo siguen vigentes ${ }^{35}$. ¿Pero cuales eran esos principios? El proyecto kantiano de "Paz Perpetua" incorporaba numerosos elementos de doctrinas precedentes pero reelaborados, que se pueden retrotraer hasta la estela reformista de Bodin, Grocio y Vattel propugnando un nuevo Derecho Internacional creado por los Estados y con carácter vinculante para ellos. Frente a esta idea, estaba la concepción hobbesiana que se basa en la defensa del Estado-nación, que es consagrado como actor exclusivo de las relaciones internacionales. En ese sentido, Kant también creía en la importancia del Estado pero orientado hacia la paz tanto en su interior como en el exterior. Kant proponía la unión de diferentes Estados unidos entre sí por una Federación que tendría como objeto mantener segura la liberad de los miembros. De este modo, era el primer autor que atribuía realidad jurídica a la idea de Estado federal a escala mundial, donde cada uno de los miembros confederados se organizaría democráticamente en su interior, aunque el propio Kant rebajaría sus pretensiones debido a la desconfianza que provocó para alcanzar tan altas y perfectas cotas de convivencia pacífica. De esta forma retrajo el ideal de Estado federal al ideal de Federación de Estados y la ausencia del principio de legalidad a un Congreso permanente de Estados, que no debían de ser únicamente republicanos y no deberían necesariamente tender hacia la paz (podría ser la actual ONU). A esto había que añadirle la contradicción sistemática existente entre la necesidad de crear normas jurídicas internacionales vinculantes y el mantenimiento de la plena soberanía de cada miembro asociado ${ }^{36}$.

La tesis de la "paz democrática" adquirió importancia tras el fin de la Guerra Fría, recuperando tres de sus ejes: a) históricamente las democracias liberales nunca o casi nunca se han hecho la guerra; b) las democracias liberales no son más propensas a la guerra que los Estados no democráticos, pero tampoco lo son menos; c)aunque las democracias liberales no se hacen la guerra entre ellas, sí han tenido conflictos armados con los Estados no liberales.

La tesis de la "paz democrática" está muy emparentada con la ideología liberal. La búsqueda de una teoría que explique por qué las democracias no hacen la guerra entre ellas puede convertirse en la búsqueda de por qué los Estados liberales han tenido tanto éxito en la organización de la fuerza. Los Estados liberales han hecho la guerra por doquier y han sido responsables de un alto grado de militarización del

35 Para el desarrollo de la crítica, ver: HABERMAS, Jürgen, "La idea kantiana de paz perpetua. Desde la distancia histórica de doscientos años", Isegoría, n¹6, mayo 1997, pp.61-90.

36 HERMOSA ANDUJAR, Antonio, "La concepción kantiana de las relaciones internacionales", Revista de Estudios Políticos, nº64, Abril-Junio 1989, pp. 163-189. 
mundo, al mismo tiempo que han contribuido a los conflictos entre los Estados no democráticos ${ }^{37}$. Otro de los problemas claves de esta tesis es su engarce con el Tercer Mundo y la precariedad e imposición de algunas de sus democracias. Por otro lado, es evidente que esta teoría respondía a la necesidad de algunos conservadores americanos para cuadrar sus diseños geopolíticos y que a lo largo de la historia había algunas excepciones como la lucha entre Gran Bretaña y EE.UU durante la crisis de Venezuela en 1895; Francia y Gran Bretaña en la crisis de Fashoda en 1898 y desde los años 30 la presencia y poder de Estados totalitarios provocó gran rivalidad entre las democracias ${ }^{38}$. A esto hay que añadirle que las democracias han sido pocas en número en los pasados doscientos años con lo que no ha habido muchas posibilidades para que luchen entre $\sin ^{39} \mathrm{y}$ hay que añadir que en las luchas de democracias contra democracias está lo que se ha denominado "terrorismo de Estado" donde muchas democracias han actuado contra gobiernos elegidos de países no desarrollados ${ }^{40}$. Por último, la tesis tiene un gran número de diferentes limitaciones debidas al concepto de democracia que se utilizan

Por tanto, la correlación entre paz y democracia era más defendible si se considera el liberalismo, no la democracia, como la bisagra de la paz entre democracias, y si se insertaba dentro de la globalización basada en el "consenso de Washington".

Paralelamente a esta, existen otras visiones de la paz democrática como la de B. Russet que inciden más en el término de cultura democrática y es más pacifista, o la escuela constructivista que defiende que los conflictos entre Estados no se derivan de la distribución del poder en el sistema internacional sino que son construidas socialmente y derivan del aprendizaje adquirido en la interacción.

Esta tesis de la "paz democrática" fue defendida en cierta medida por autores como Kagan o Fukuyama, quien se basaba en Hegel, el cual negaba la propuesta de Kant de una paz universal. Fukuyama tiene la concepción de "estado de naturaleza", es decir, hobbesiana y hegeliana, donde los Estados se manejan a su antojo según sus intereses.

37 PEÑAS, Francisco Javier, "Liberalismo y relaciones internacionales: la tesis de la paz democrática y sus críticos", Isegoría, n¹6, mayo 1997, pp. 136-137. Ver también LATHAM, R., "Democracy and War Making: Locating the International Liberal Context”, Millenium. Journal of International Studies, vol. 22, $\mathrm{n}^{\circ} 2,1993$.

38 HARRIES, Owen, "Is the Cold War Really Over?", National Review, November 10, 1989, p. 45.

39 MEARSHEIMER, John J., "Back to the future. Inestability in Europe after the cold war", International Security, Vol. 15, $\mathrm{n}^{\circ} 1$, Summer 1990, pp. 5-56.

40 RUSSET, Bruce, Grasping the democratic peace. priciples for a post-cold war world, Princeton University Press, Princeton, 1992, pp. 119-149. 
En 1999 con las movilizaciones en contra de la OMC en Seatlle se puso en marcha el movimiento antiglobalización, con el desarrollo del lema "Otro mundo es posible", con lo que las nuevas izquierdas sociales dieron forma a una sociedad civil transnacional sustentada en estos movimientos con la idea de "otro mundo es posible". Con esto lograba voz en el debate intelectual y político la otra globalización, la de la misera, del $80 \%$ población y en donde el $33 \%$ se muere de hambre ${ }^{41}$. Por otro lado, la globalización ha erosionado los gobiernos nacionales y ha generado procesos de regionalización superpuestos ${ }^{42}$

Estos movimientos certificaron el fin de la idea de que no hay alternativas, poniendo en jaque mate el modelo de globalización existente. Las ideas altermundistas apoyan y favorecer el desarrollo de campañas concretas sobre objetivos limitados, proponiendo una estrategia no teleológica. De tal forma, defienden a la persona humana y a la sociedad y sus derechos fundamentales ${ }^{43}$, tales como una democracia participativa, una reorganización de las grandes instituciones internacionales y la creación de un parlamente mundial que llevarían a una sociedad pacífica y donde fuera posible el "no-killing".

\section{EL DESARROLLO DE LA IDEA DE PAZ DENTRO DE UN RELATO HISTÓRICO NO TELEOLÓGICO.}

Como se ha demostrado en este trabajo, desde una óptica tradicional la historia tiene una estructura teleológica hacia un punto determinado tanto a nivel individual (desarrollo objetivos individuales), colectivo (sociedades utópicas ya sean liberales o socialistas), cultural, económico, político y social, basados en una idea de progreso determinada y con unos "organizadores" siempre fijos.

En buena medida, la concepciones teleológicas son reflejo de una crisis social y se muestran con expresiones como el propio "fin del mundo", "milenarismo" o "fin de la Historia". Suele ser una justificación de una sociedad existente y del desarrollo alcanzado en algún territorio como el más completo y racional. Lo único que hacen

41 VALENTI, Esteban, "Dos globalizaciones", Rebelion.org, 15 de julio de 2002, [ [consulta 15 de julio de 2002].

42 Hay autores que defienden que la globalización ha reducido la pobreza, basándose sobre todo en China y Asia Un ejemplo es MOSBACHER, Michael, "La globalización reduce la pobreza", Libertaddigital.com, 21 de diciembre de 2002, [http://www.libertaddigital.com/./opiniones/ opi_desa_11862.html], [21 de diciembre de 2002].

43 Ver François Houtart y François Polet, El otro Davos. Globalización de resistencias y de luchas, pp. 54-55. 
los constructos teleológicos es privilegiar una historia particular. La teoría y la práctica; la filosofía y la realidad están íntimamente relacionadas y ambas se retroalimentan. Por tanto, la evolución histórica está abierta a un proceso que nunca acaba.

Lo que se ha dejado claro es que la historia está formada por diferentes y diversos procesos, no coherentes y no direccionales regidos por una idea de progreso o regreso consecuencia de la labor individual y colectiva de los seres humanos, y que responden a unos "organizadores" cambiantes y móviles en base a objetivos concretos y no a grandes metas. En ese sentido y en ese marco teórico y metodológico es donde puede operar perfectamente el "no-killing", puesto que es un planteamiento basado en una resolución y un objetivo práctico (no matar) y no en una gran utopía como puede ser la paz universal o la "gran paz".

A) Abandono de la linealidad. No hay un único orden final de las cosas ni está preestablecido. Hay que recordar que el concepto de la clase dominante ha sido siempre el espejo gracias a los cuales se ha venido a constituir la imagen de un orden. La renuncia de la linealidad lleva a escapar del eurocentrismo y el determinismo, que están asociados al capitalismo, al imperialismo y a la modernidad. En otro sentido, ayuda a entender la existencia de diferentes pasados, presentes y futuros (posibles).

B) Una "nueva idea de progreso" más sintética, menos dogmática, de más perspectiva y con una fuerte impronta moral y ética. Una nueva idea de progreso no teleológica con continuidades y rupturas y que coloca al ser humano en el centro de la historia. Es una idea de progreso con varias vías, sin determinismo y con diferentes opciones ${ }^{44}$.

C) Los motores de la historia deben de ser plurales y adaptados a cada momento: la acción política común, los movimientos sociales, los seres humanos, las naciones, los Estados. Al igual que no existen motores fijos en la Historia tampoco existe un determinismo histórico, y sí un probabilismo histórico, en el que el riesgo es algo inevitable. Esto posibilita el paso de una ciencia amoral a una ciencia éticamente responsable, desde una tecnología dominadora del hombre a una tecnología al servicio del hombre, y desde una democracia jurídico-formal a una democracia viva que garantize la libertad, la justicia y el "no-killing"45.

44 BARROS, Carlos, "La historia que viene" en Actas Congreso Internacional Historia a Debate, Tomo I, p. 101.

45 KÚNG, Hans, Proyecto de una ética mundial, Trotta, Madrid, 1991; LÓPEZ PETIT, Santiago, Horror Vacui. La travesía de la noche del siglo, Siglo XXI, Madrid, 1996. Gracias a Carlos Otero por la referencia. 
D) Todas estas cuestiones abren la posibilidad de una nueva modernidad(es) alternativas, construidas con todas estas bases de intercambio y mestizaje metodológico y considerando que tiene que ser pluriversal, decolonial y no eurocéntrica. Esto es clave para abandonar las explicaciones teleológicas por otras más contingentes, con el objeto de pensar con varias ideas y la vez, y de una manera dialógica y compleja.

E) El "no-killing" es una táctica y una estategia social y política que lleva a presupuestos pacíficos. Parte de presupuestos de la historia de la paz y de las experiencias de regulacion pacífica a lo largo de la historia para convertirlos en filosofia y teoría de la accion práctica comprometida con el cambio social. Pretende ser un sistema y un instrumento de lo más util y eficaz para conseguir la paz. Es ademas la utilizacion de medios pacificios para resolver los conflictos, buscando los puntos de encuentro con los otros pero sin dañar, sin lastimar y sin arruinar a los adversarios. Es una forma constructiva y creativa de hacer la historia . La historia del "no killing" está alimentando la historia de la paz. El "no killing" se encuentra en corrientes filosoficas, religiosas o éticas, que llevan máximo respecto por las personas, utilizacion de la persuasión antes que la coerción y una práctica continuada 